\title{
ADHD and the Importance of Comorbid Disorders in the Psychosocial Development of Children and Adolescents
}

\author{
Evangelia Antoniou ${ }^{1,2}$, Nikolaos Rigas ${ }^{1}$, Eirini Orovou1, Alexandros Papatrechas ${ }^{2}$ \\ ${ }^{1}$ Department of Midwifery, University of West Attica, Athens, Greece \\ ${ }^{2}$ Non-Profits/Non-Governmental Organizations (NGO) "Fainareti”, Athens, Greece \\ Email: *lilanton@uniwa.gr
}

How to cite this paper: Antoniou, E., Rigas, N., Orovou, E. and Papatrechas, A. (2021) $\mathrm{ADHD}$ and the Importance of Comorbid Disorders in the Psychosocial Development of Children and Adolescents. Journal of Biosciences and Medicines, 9, 1-13. https://doi.org/10.4236/jbm.2021.94001

Received: February 26, 2021

Accepted: March 28, 2021

Published: March 31, 2021

Copyright $\odot 2021$ by author(s) and Scientific Research Publishing Inc. This work is licensed under the Creative Commons Attribution International License (CC BY 4.0).

http://creativecommons.org/licenses/by/4.0/ (c) (i) Open Access

\begin{abstract}
The attention deficit hyperactivity disorder (ADHD), one of the most common disorders in the childhood and adolescence population, but also in the reproductive period, affects and influences learning, social relations and their quality of life. There are strong neuropathological similarities between ADHD and various concomitant psychiatric conditions. ADHD frequently coexists with learning and language disabilities, sleep disorders, impulse control personality and anxiety disorders, intellectual disability, substance use disorders and mood disorders, as well as autism spectrum disorders and tic disorders. The overlapping symptoms of ADHD and other morbidities constitute challenges but also an imperative need for the experts to be able to detect and clarify so as to achieve the proper diagnosis and the relative treatment. The expression of the disease differs accordingly depending on the age group and the presence of comorbidities. In school-age, symptoms of ADHD include inattention, hyperactivity, and impulsivity. In adolescence, depending on the gender, hyperactivity decreases but the problems in learning and psychopathology still remain. Therefore, it is recommended that when ADHD coexists with other psychopathologies in childhood and adolescence to first and directly treat the most weakened condition so that the child or the adolescent can change the course of their psychiatric morbidity and improve their ability to function and socialize.
\end{abstract}

\section{Keywords}

ADHD, Psychiatric Comorbidity, ADHD and Children, ADHD and Adolescents 


\section{Prevalence and Risk Factors}

$\mathrm{ADHD}$ is one of the most common behaviour disorders and the most frequent neurodevelopmental disorder of childhood. The prevailing view is that ADHD is inherited, determined by various genetic factors and is shaped by various mental and neuropsychological dysfunctions and inadequacies. According to DSM-V, ADHD along with Conduct Disorder and Oppositional Defiant Disorder is included in the category "Disorders of Inattention and Disruptive Behaviour". They are first diagnosed during infancy, childhood or adolescence while the first symptoms are seen in the 3rd year of age [1]. The symptoms differentiate depending on the developmental stages and it is characterized by unfitting for the age inattention, hyperactivity and impulsivity. Symptoms become more apparent in kindergarten and later in primary school, while in adolescence hyperactivity decreases but learning problems and psychopathology still remain. It is calculated that the percentage of childhood children with ADHD comes up to 3\% $7 \%$ with the boys-to-girls ratio ranging from 3:1 up to 5:1 [2]. There are three subtypes of ADHD: combined, inattentive and hyperactive/impulsive [3].

\section{ADHD Symptoms}

The basic ADHD symptoms are Inattention, Hyperactivity and Impulsivity. These symptoms constitute characteristics of many children, but in ADHD children they are more strongly manifested. Therefore, conditions easily managed by children without the disorder create special difficulties in ADHD children. There are differences in the developmental level of ADHD children along the axes: 1) attention focusing, 2) activity control and 3) impulse control [4].

\subsection{ADHD in Childhood}

After monitoring ADHC children, high inattention and hyperactivity have been identified as an integral part of the disorder in childhood [5] [6] [7]. These characteristics, along with impulsivity, are more apparent in school age; a fact that prevents children from adapting to the school environment and interact with their peers. Childhood is the period when behaviour and mental disorders are manifested [8] [9]. ADHD symptoms in childhood are responsible for the prevention of developing qualitative and quantitative social interactions. There is a difficulty, thus, in the development of social relations while communication with parents is also characterized as problematic [10]. Furthermore, dysfunctions are also observed in other childhood fields. For example, children find difficulties in cording activities that require broad and refined activity [11], verbal and non-verbal working memory and mental calculations [12]. They cannot narrate a story, do not have verbal fluency and proper use of arguments, while they have difficulties in the development, application and self-check of organization strategies and self-regulation of their feelings [13] (Table 1). 
Table 1. ADHD symptoms in childhood.

\begin{tabular}{|c|c|c|}
\hline Inattention & Hyperactivity & Impulsivity \\
\hline $\begin{array}{l}\text { Strong in attention by audiovisual } \\
\text { stimuli Main ADHD }\end{array}$ & $\begin{array}{l}\text { Fidgeting or squirming } \\
\text { and not sitting still }\end{array}$ & $\begin{array}{l}\text { Answering impulsively before } \\
\text { the question has been completed }\end{array}$ \\
\hline Day dreaming in the class & $\begin{array}{l}\text { Standing up even when they } \\
\text { must be sitting }\end{array}$ & $\begin{array}{l}\text { Are annoyed when they } \\
\text { have to wait for their turn }\end{array}$ \\
\hline Not easily focusing on details & $\begin{array}{l}\text { Constantly moving and } \\
\text { characterized as restless }\end{array}$ & Moving either fast or slowly \\
\hline $\begin{array}{l}\text { Facing difficulties in organizing their } \\
\text { activities or their schedule }\end{array}$ & $\begin{array}{l}\text { Constantly moving and } \\
\text { characterized as restless }\end{array}$ & $\begin{array}{l}\text { Interrupting others or } \\
\text { others' activities }\end{array}$ \\
\hline $\begin{array}{l}\text { Not fully following instructions and } \\
\text { frequently failing to turn in their } \\
\text { homework assignments }\end{array}$ & Talking in the class & \\
\hline Often forgetting their daily activities & Playing recklessly & \\
\hline \multicolumn{3}{|l|}{ Appearing not to be } \\
\hline listening when spoken to & & \\
\hline
\end{tabular}

\subsection{ADHD in Adolescents}

Many of the ADHD-diagnosed children continue to manifest symptoms in adolescence at a percentage of $85 \%$. Of course, there is a decrease in the degree of hyperactivity, but inattention, impulsivity and internal disquiet still remain, resulting in decreased school performance and increased conflicts with the parents and the social environment [14]. A longitudinal study of twins [15] showed that the factors affecting ADHD manifestation in childhood and are responsible for their continuation in adolescence are the same. Furthermore, another study showed that $70 \%-80 \%$ of the children characterized by hyperactive disorders also maintain them in their adolescence [16]. With regard to the manifestation and progress of the hyperactive syndrome in adolescence, it seems that $25 \%-45 \%$ of hyperactive adolescents present oppositional defiant disorder and 30\%-58\% have low school performance to such a degree that they are required to repeat the class [17]. Apart from school performance problems, there are various forms and manifestations of psychopathology leading to substance abuse in adolescence [18]. It is usual many adolescents fulfilling the ADHD criteria to have antisocial behaviour and feel disappointed due to rejection by the school environment. For this reason, a big percentage of ADHD adolescents are characterized by low self-esteem leading to depressive disorders [19] [20]. A study comparing preadolescent ADHD girls with a relevant control group of girls without disorders showed that apart from significant differences in cognitive and executive functions, and difficulties in interpersonal relations, the disorder of the affected adolescents was linked to a history of adoption, abuse and strict upbringing with a strong element of criticism and punishment by their parents [21].

\section{Comorbidity}

ADHD does not usually present isolated, but it is commonly accompanied by 
other disorders. The coexistence of ADHD with another disorder is possible to affect to a big degree the psychosocial development of children, while the progression and treatment of ADHD becomes more complex. Psychiatric comorbidities are frequent in ADHD children, the majority of whom are diagnosed with at least 1 comorbidity [22] [23] [24]. If ADHD is not properly treated, many difficulties are created in the school, family and social environment, resulting in low school performance, anxiety, low self-esteem, aggressive behaviour, dysfunctioning social relations and rejection by others. Comorbid ODD in childhood can lead to substance use and anti-social delinquent behaviour in adolescence [25]. So, the purpose of this study was to investigate the co-occurrence of ADHD, resulting in the awakening of teachers and health professionals who work with children and adolescents, in order to recognize through psychiatric disorders, the hidden presence of ADHD. There 10 categories of comorbid conditions [26] (Figure 1) that are usually diagnosed along with ADHD and are manifested in the entire range of severity. The causes as well as their symptoms are various and include gene exposure to environmental toxins and perinatal condition [27]. With regard to adolescents and adults with LD and ADHD, research has shown that the patients have constant and unique characteristics manifested in various ways, as development and age-related demands change. For example, adolescents with Specific language impairment (SLI) are more at risk for emotional and behavioral problems compared to their peers without ADHD [28].

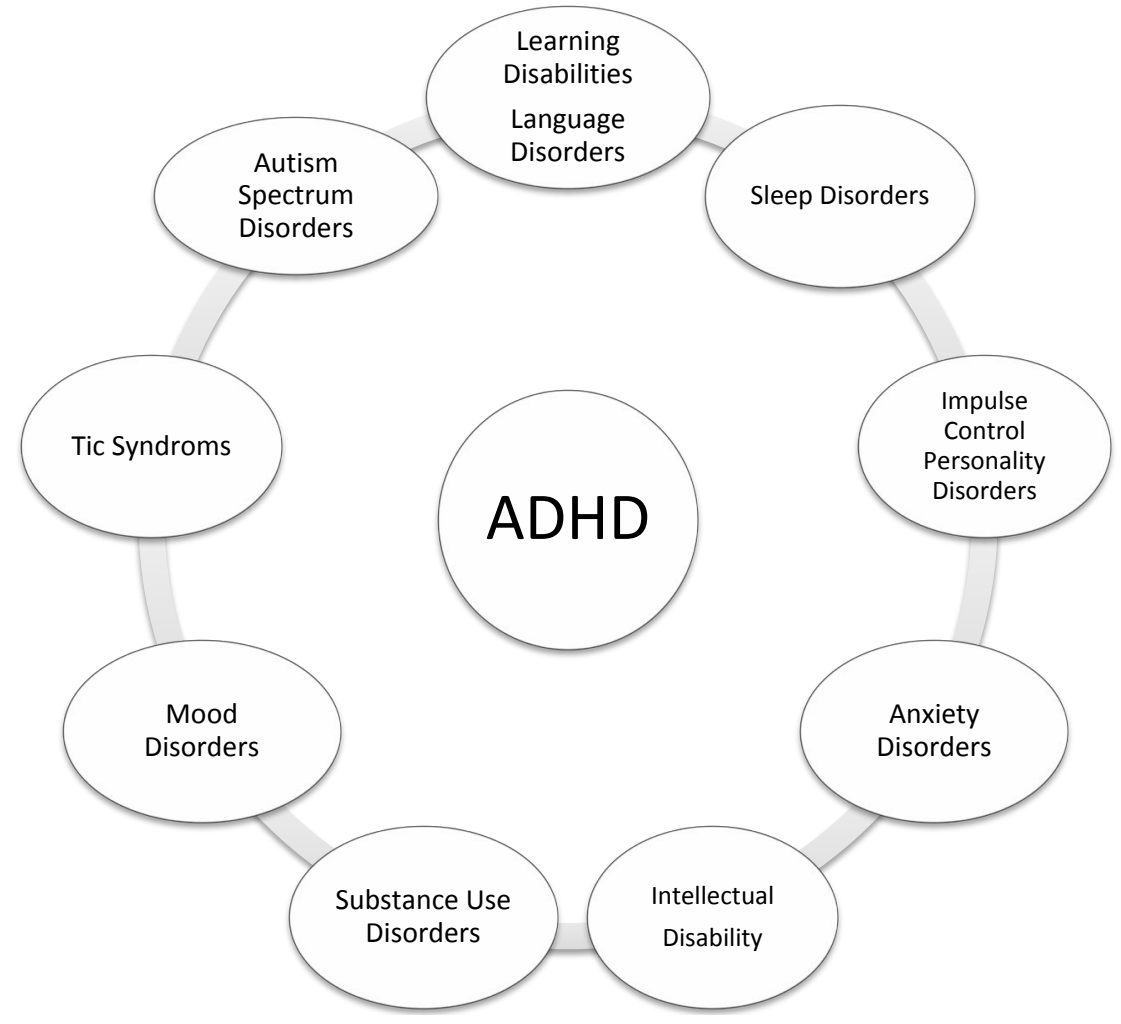

Figure 1. ADHD and comorbidity. 


\subsection{Learning Disabilities/Language Disorders}

Various studies report high comorbidity among ADHD children and learning disabilities. A percentage of $15 \%-50 \%$ of these disabilities are related to reading, $24 \%-60 \%$ to math, $25 \%-50 \%$ oral speech, and $20 \%-51 \%$ written word [28]. Many researchers studied the hypothesis that ADHD and Learning Disabilities have a common causal mechanism. This mechanism seems to have a neurological substrate and is affected to a big degree by genetic factors [29]. This hypothesis was based on research that found deficits in common cognitive mechanisms, such as information processing speed, memory, attention function, and genetic factors relating to ADHD careless behaviour [30] [31]. ADHD affects the detection, assessment, treatment and study of children's language disorders (LD). Speech and language disorders in ADHD persons range from $8 \%$ to $90 \%$ and are related to deficits in structural communication elements, such as the use of punctuation and phonology [32]. With regard to adolescents and adults with LD and ADHD, research has shown that the patients have constant and unique characteristics manifested in various ways, as development and age-related demands change. For example, adolescents with Specific language impairment (SLI) are more at risk for emotional and behavioral problems compared to their peers without ADHD [33].

\subsection{Sleep Disorders}

Almost 3 in 4 children suffer from sleep disorders. These disorders are related to circadian rhythm disturbances, obstructive sleep apnea, peripheral limb movement disorder and restless legs syndrome [34]. The restless legs syndrome is a motor disorder characterized by the involuntary movement of the legs, many times reported in other parts of the body as well. Circadian rhythm disturbances involve a problem in the timing when a person sleeps and is awake caused by alterations of the circadian time-keeping system and the external environment. The obstructive sleep apnea is characterized by partial or full obstruction of the upper airways, leading to sleep disturbance. A history of snoring or possible obstructive sleep apnea in childhood is associated with double the possibility of ADHD diagnosis or symptoms in adulthood [35]. The above sleep disorders can result in significant functional disorders affecting the mood, attention, behaviour, school performance, and, finally the quality of life [36]. In an affected person, sleep disorders can result in sleep restriction or fragmentation and can lead to excessive fatigue during the day and also affect the mood, attention, behaviour and physical health, which are critical for school/work performance and quality of life. Furthermore, while adults may seem tired, when they have not slept, fatigue in children is often manifested with excessive ADHD symptoms: hyperactivity-impulsiveness - and sometimes even aggressiveness [34].

\subsection{Impulse Control Personality Disorders}

There are five types of Impulse Control Disorders (ICD): Oppositional defiant 
disorder (ODD), Antisocial Personality Disorder (APD), Conduct Disorder (CD), Borderline Personality Disorder (BPD) and Intermittent Explosive Disorder (IED) [26]. ODD is characterized by a pattern of negation, disobedience and hostile behaviour towards parents, teachers and other adults. Oppositional behavior is a normal part of children's development in early childhood and adolescence. However, the hostile behaviour becomes disconcerting, when it is particularly frequent and becomes distinct compared to children of the same developmental level, and when it affects the social, family and academic life of a child or adolescent. ODD symptoms may include: excessive arguing with adults, often being touchy or easily annoyed by others, blaming others for his or her mistakes or misbehavior, frequent temper tantrums, spiteful attitude and revenge seeking, mean and hateful talking when upset and active defiance and refusal to comply with adult requests and rules. $1 \%-16 \%$ of all school-age children and adolescence have ODD [37]. ODD shows high morbidity and dysfunction with significant impact for the future, if not treated early [38]. Moreover, ADHD children have increased possibilities to develop APD at a later age. APD people do not follow the rules of society and do not respect the rights of others. People with such a personality type can participate in criminal activities [39]. BPD is a very common comorbid ADHD disorder. The symptom overlapping between ADHD and BPD for adults includes impulsiveness, emotional dysregulation and interpersonal impairment, a fact that makes differential diagnosis difficult. BPD concerns $1.6 \%$ of the general population, while $14 \%$ of the ADHD children will later be diagnosed with BPD [40]. The incidence of Impulse Control Personality Disorders in girls is almost half and these disorders often constitute the main reason of referring boys for evaluation. Girls in adolescence are more possible to become restless, depressive and socially retreated with high sexual activity [41]. IED is a less known mental disorder characterized by episodes of unexplained anger. It is commonly described as "flying into a rage for no reason". It is estimated that $1 \%$ to $7 \%$ of the people will present intermittent explosive disorder in their lives [39]. IED reflects the repeated actions of impulsive-aggressive explosions (verbal or physical against people, animals or objects), which are clearly disproportionate to the given situation [42]. ADHD is an extrovert disorder which has received increased attention in the research on juvenile delinquency. ADHD children present an increased risk of being involved in criminal actions whereas $26 \%-30 \%$ of juvenile detention samples show increased ADHD prevalence percentages [43].

\subsection{Anxiety Disorders}

Anxiety disorders both in children and adolescents are included in the disorders more frequently occurring with [44]. There are 5 types of anxiety disorders: Generalized Anxiety Disorder (GAD), Social and Specific Phobia (SP), Obsessive Compulsive Disorder (OCD), Panic Disorder and Agoraphobia [26]. ADHD and anxiety disorders share common neurobiological dysfunctions, but also have 
different neurobiological abnormalities suggesting that they are different diagnoses. These patients are less possible to benefit only by cognitive behavioral treatment strategies and are more often in need of complementary medication [45]. Usually, a person with ADHD will suffer in average from approximately 9 anxiety symptoms, but these usually defy an official diagnosis. Many people, therefore, are not diagnosed with anxiety and do not receive the appropriate treatment. Furthermore, ADHD people have also fears based on real events in their lives. ADHD people are not sure about their abilities, are usually inconsistent and feel that they cannot cope with the school or in various social groups. It is natural, therefore, to live in a state of high stress and fear without this showing necessarily a stress disorder. With regard to adolescence, the reactive and anticonventional behaviour is followed by consequences. ADHD women often have feelings of shame as they remember behaviors in their adolescence [46].

\subsection{Intellectual Disability}

Intellectual Disability (ID) is characterized by a deficit of the intellectual ability affecting intellectual functioning and adaptive functioning [47]. Intellectual functioning is evaluated with tests by the physician and with standardized tests. A full-scale IQ of about 70 to 75 shows a significant limitation in intellectual functioning. Not many things are known about the clinical picture and cause of ADHD in children with intellectual disability (ID), due to the fact that people with lower cognitive ability (IQ score $<70$ ) are often excluded from ADHD studies. Studies have shown that ADHD is more often manifested in these children, but it may not be diagnosed because the key ADHD symptoms are overshadowed. There is a tendency of the clinicians to ignore the comorbidity after diagnosing ID [48].

\subsection{Substance Use Disorders}

Adolescents with substance-use disorders and attention deficit/hyperactivity disorder (ADHD) are more and more often seen in clinical practice. In particular, in a recent study $23 \%$ of the young adult substance users seeking treatment also suffered from ADHD [49]. ADHD children have been found to run an increasing risk of SUD. The risk of SUD has been proven to be double among ADHD people and four times higher among those with ADHD and comorbid conduct disorder [50]. Furthermore, adolescent girls diagnosed with ADHD are involved in "risky" behaviors, such as substance abuse, to a higher degree than men [41].

\subsection{Mood Disorders}

In the context of $\mathrm{ADHD}$ characteristics, the child grows up in a setting of school failure, rejection by their peers and criticism by the family members, and, therefore, the natural consequence is to develop Mood Disorders [51]. Mood disorders include: Major Depressive Disorder (MDD), Bipolar Disorder (BD), Dys- 
thymic Disorder (DD) and Cyclothymic Disorder (CD) [52]. DD can be characterized as a chronic low-intensity depression with persistent irritability and, frequently, low self-esteem. MDD is a more severe form of depression that can be manifested in ADHD children and even, more frequently in adults. ADHD in childhood is a prognostic factor for the development of MDD in adulthood [53]. DD and MDD usually develop several years after a child has been diagnosed with $\mathrm{ADHD}$ and, if left untreated, they can deteriorate overtime. BD is a severe mood disorder that has been recently recognized that it is presented in children. Contrary to adults, children with BD present a more complex disorder of extreme emotional instability, behavioral difficulties and social problems. BD is difficult to be diagnosed in ADHD children because the symptoms of the two disorders are similar a lot [54]. The research and clinical experience show that adolescent girls and women of reproductive age suffering from ADHD have high percentages of anxiety and depression coexistence that are more possible to be diagnosed in relation to the underlying ADHD. It seems that the tendency of women to internalize the symptoms and withdraw socially, helps the differential diagnosis of the symptoms of inattention. Compared to adolescent boys, girls with ADHD report more anxiety, more agony, more depression symptoms and an external locus of control. It was found out that they run the risk for more psychological disorders. In a national research, $14 \%$ of adolescent girls with ADHD were found to have been subjected to anti-depressant treatment prior to ADHD treatment compared with only $5 \%$ of the boys with ADHD [41].

\subsection{Tic Syndromes}

Duplicate the Tics are defined as repeated, sudden, quick, non-rhythmical muscular movements, including sounds or voices. The Tourette syndrome is diagnosed when people have both motor and vocal tics for more than 1 year. Tics are treated only when interfering in the activities or the self-image of children. Treatment can include behavioural intervention for tics and antipsychotic medication. The severity of tics varies to a big degree. They are seen in about $20 \%$ of children most of whom have not been evaluated or diagnosed. The Tourette syndrome, the most severe type, is seen in 3 up to 8 in 1000 children. The men to women ratio in adolescence is 3:1 [55].

\subsection{Autism Spectrum Disorders}

This template was designed for two affiliations. A recent research has shown high comorbidity percentages for ADHD and Autism Spectrum Disorders (ASD) and difficulties relating to differential diagnosis. ADHD and ASD are the most difficult development disorders to distinguish one from the other [5]. According to DSM-5, the ADHD diagnosis may exclude the ASD diagnosis and vice versa, but ADHD as well as the Autism Spectrum Disorders (ASD), with autism being the main representative, have many common characteristics, such attention deficit, hyperactivity and deficient social skills. ADHD children find difficulties in their socialization and ASD children find difficulties in maintain- 
ing their attention and self-control [30]. There are though clinical pictures of children not fully justified by the ADHD or ASD diagnostic criteria. Indeed, due to the co-existence of the symptoms of attention deficit, hyperactivity and social deviations, there is the fear and the possibility that children with ASD to be erroneously diagnosed having $\mathrm{ADHD}$ and, thus, the treatment of their autism may be significantly delayed [56]. Seeking various researches, we discover that the epidemiological data, regarding ADHD and ASD comorbidity, differ depending on the study. There was one study that concluded that $20 \%-50 \%$ of the ADHD children fulfill the criteria for ASD as well, while $30 \%-80 \%$ of the ASD children fulfill the criteria for ADHD while another one found out that ADHD children have higher percentages of autism symptoms compared to the developing children and the children with psychiatric disorders [57]. Indeed, recent studies with twins and families showed that these disorders are attributed to the same genetic factors. ADHD and autism share the same position in chromosome 16p13, are due to the dysfunction of common cerebral regions and have a common genetic background. Therefore, a child with ASD and ADHD shall exhibit more ADHD symptoms [58].

\section{Conclusion}

The purpose of this study was to investigate the co-occurrence of ADHD, resulting in the awakening of teachers and health professionals who work with children and adolescents, in order to recognize through psychiatric disorders, the hidden presence of ADHD. Children developing ADHD suffer from comorbid psychiatric disorders. Indeed, the spectrum of comorbid psychiatric disorders is so wide and their symptoms are so noisy that they can overwhelm ADHD. Non-sufficient diagnosis of ADHD in childhood can be an obstacle for the proper psychosocial development of an adolescent. Depression, substance use and low performance in school chores, disappointment and antisocial behaviour are characteristic signs of untreated ADHD in adolescence. The significance of the proper diagnosis in childhood results in the decrease of the intensity of the symptoms, the proper personalized therapeutic approach and, finally, the ensuring of a qualitative school, social and emotional life. The transition to adolescence, a period of intense hormonal changes and, therefore, emotional reactions is experienced with a different degree of intensity by each adolescent and depending on the gender. The presence of psychiatric comorbid conditions complicates undiagnosed ADHD and contributes to the creation of socially, psychologically and emotionally suffering adults. ADHD diagnosis is not only about childhood. The timely diagnosis ensures smoother adolescence and adult life, while ADHD comorbidity, in combination with the gender and age group, can contribute to the inflation of psychosocial problems, burdening public health and the economic indices.

\section{Conflicts of Interest}

The authors declare no conflicts of interest regarding the publication of this paper. 


\section{References}

[1] Pelham, W.E., Gnagy, E.M., Greiner, A.R., Hoza, B., Hinshaw, S.P., Swanson, J.M., Simpson, S., Shapiro, C., Bukstein, O., Baron-Myak, C. and McBurnett, K. (2000) Behavioral versus Behavioral and Pharmacological Treatment in ADHD Children Attending a Summer Treatment Program. Journal of Abnormal Child Psychology, 28, 507-525. https://doi.org/10.1023/A:1005127030251

[2] Faraone, S.V., Sergeant, J., Gillberg, C. and Biederman, J. (2003) The Worldwide Prevalence of ADHD: Is It an American Condition? World Psychiatry, 2, 104-113.

[3] (2017) What Are the 3 Types of ADHD? ADDitude.

[4] Wilens, T.E. and Spencer, T.J. (2010) Understanding Attention-Deficit/Hyperactivity Disorder from Childhood to Adulthood. Postgraduate Medicine, 122, 97-109. https://doi.org/10.3810/pgm.2010.09.2206

[5] Diagnostic and Statistical Manual of Mental Disorders Source Information. https://www.nlm.nih.gov/research/umls/sourcereleasedocs/current/DSM4/index.ht $\underline{\mathrm{ml}}$

[6] Faraone, S.V. and Mick, E. (2010) Molecular Genetics of Attention Deficit Hyperactivity Disorder. Psychiatric Clinics of North America, 33, 159-180. https://doi.org/10.1016/j.psc.2009.12.004

[7] DuPaul, G.J. and Stoner, G. (2004) ADHD in the Schools: Assessment and Intervention Strategies. Second Edition, Guilford Press, New York.

[8] Pham, A.V. and Hasson, R.M. (2014) Verbal and Visuospatial Working Memory as Predictors of Children's Reading Ability. Archives of Clinical Neuropsychology, 29, 467-477. https://doi.org/10.1093/arclin/acu024

[9] Rosenberg, J., Pennington, B.F., Willcutt, E.G. and Olson, R.K. (2012) Gene by Environment Interactions Influencing Reading Disability and the Inattentive Symptom Dimension of Attention Deficit/Hyperactivity Disorder. Journal of Child Psychology and Psychiatry, 53, 243-251. https://doi.org/10.1111/j.1469-7610.2011.02452.x

[10] CDC (2021) Use of ADHD Medicine Is Increasing among Pregnant Women. CDC. https://www.cdc.gov/pregnancy/meds/treatingfortwo/features/keyfinding-ADHDmed-increase.html

[11] National Research Council (US) and Institute of Medicine (US) Committee on Depression, P.P., England, M.J., Sim, L.J. (2009) Associations Between Depression in Parents and Parenting, Child Health, and Child Psychological Functioning. National Academies Press (US), Washington DC.

[12] Junod, R.E.V., DuPaul, G.J., Jitendra, A.K., Volpe, R.J. and Cleary, K.S. (2006) Classroom Observations of Students with and without ADHD: Differences across Types of Engagement. Journal of School Psychology, 44, 87-104. https://doi.org/10.1016/j.jsp.2005.12.004

[13] DuPaul, G.J., Jitendra, A.K., Tresco, K.E., Junod, R.E.V., Volpe, R.J. and Lutz, J.G. (2006) Children with Attention Deficit Hyperactivity Disorder: Are There Gender Differences in School Functioning? School Psychology Review, 35, 292-308. https://doi.org/10.1080/02796015.2006.12087993

[14] Nicolson, R.I. and Fawcett, A.J. (2007) Procedural Learning Difficulties: Reuniting the Developmental Disorders? Trends in Neurosciences, 30, 135-141. https://doi.org/10.1016/j.tins.2007.02.003

[15] Verret, C., Guay, M.-C., Berthiaume, C., Gardiner, P. and Béliveau, L. (2012) A Physical Activity Program Improves Behavior and Cognitive Functions in Children 
with ADHD: An Exploratory Study. Journal of Attention Disorders, 16, 71-80. https://doi.org/10.1177/1087054710379735

[16] Larsson, J.-O., Larsson, H. and Lichtenstein, P. (2004) Genetic and Environmental Contributions to Stability and Change of ADHD Symptoms between 8 and 13 Years of Age: A Longitudinal Twin Study. Journal of the American Academy of Child and Adolescent Psychiatry, 43, 1267-1275.

https://doi.org/10.1097/01.chi.0000135622.05219.bf

[17] Biederman, J., Faraone, S.V. and Monuteaux, M.C. (2002) Differential Effect of Environmental Adversity by Gender: Rutter's Index of Adversity in a Group of Boys and Girls with and without ADHD. American Journal of Psychiatry, 159, 1556-1562. https://doi.org/10.1176/appi.ajp.159.9.1556

[18] Galéra, C., Melchior, M., Chastang, J.-F., Bouvard, M.-P. and Fombonne, E. (2009) Childhood and Adolescent Hyperactivity-Inattention Symptoms and Academic Achievement 8 Years Later: The GAZEL Youth Study. Psychological Medicine, 39, 1895-1906. https://doi.org/10.1017/S0033291709005510

[19] Klassen, A.F., Miller, A. and Fine, S. (2004) Health-Related Quality of Life in Children and Adolescents Who Have a Diagnosis of Attention-Deficit/Hyperactivity Disorder. Pediatrics, 114, e541-e547. https://doi.org/10.1542/peds.2004-0844

[20] Young, S., Chadwick, O., Heptinstall, E., Taylor, E. and Sonuga-Barke, E.J.S. (2005) The Adolescent Outcome of Hyperactive Girls. Self-Reported Interpersonal Relationships and Coping Mechanisms. European Child \& Adolescent Psychiatry, 14, 245-253. https://doi.org/10.1007/s00787-005-0461-z

[21] (2009) Women, Hormones, and ADHD. ADDitude.

[22] Hodgkins, P., Setyawan, J., Mitra, D., Davis, K., Quintero, J., Fridman, M., Shaw, M. and Harpin, V. (2013) Management of ADHD in Children across Europe: Patient Demographics, Physician Characteristics and Treatment Patterns. European Journal of Pediatrics, 172, 895-906. https://doi.org/10.1007/s00431-013-1969-8

[23] Rowland, A.S., Umbach, D.M., Stallone, L., Naftel, A.J., Bohlig, E.M. and Sandler, D.P. (2002) Prevalence of Medication Treatment for Attention Deficit-Hyperactivity Disorder among Elementary School Children in Johnston County, North Carolina. American Journal of Public Health, 92, 231-234. https://doi.org/10.2105/AJPH.92.2.231

[24] Spruyt, K. and Gozal, D. (2011) Sleep Disturbances in Children with AttentionDeficit/Hyperactivity Disorder. Expert Review of Neurotherapeutics, 11, 565-577. https://doi.org/10.1586/ern.11.7

[25] Teenagers with ADD-A Parents' Guide. https://addwarehouse.com/teenagers-with-add.html

[26] Psychiatric Comorbidities in Patients with ADHD. ADHD Institute.

[27] Silver, L. (2017) When It's Not Just ADHD: Symptoms of Comorbid Conditions. ADDitude.

[28] Claude, D. and Firestone, P. (1995) The Development of ADHD Boys: A 12-Year Follow-Up. Canadian Journal of Behavioural Science, 27, 226-249. https://doi.org/10.1037/0008-400X.27.2.226

[29] Bertin, M. (2015) Mindful Parenting for ADHD: A Guide to Cultivating Calm, Reducing Stress, and Helping Children Thrive. New Harbinger Publications, Oakland.

[30] Mayes, S.D., Calhoun, S.L. and Crowell, E.W. (2000) Learning Disabilities and ADHD: Overlapping Spectrumn Disorders. Journal of Learning Disabilities, 33, 417-424. https://doi.org/10.1177/002221940003300502 
[31] Eden, G.F. and Vaidya, C.J. (2008) ADHD and Developmental Dyslexia: Two Pathways Leading to Impaired Learning. Annals of the New York Academy of Sciences, 1145, 316-327. https://doi.org/10.1196/annals.1416.022

[32] Hawkins, E., Gathercole, S., Astle, D., et al. (2016) Language Problems and ADHD Symptoms: How Specific Are the Links? Brain Sciences, 6, 50.

https://doi.org/10.3390/brainsci6040050

[33] Conti-Ramsden, G., Mok, P.L.H., Pickles, A. and Durkin, K. (2013) Adolescents with a History of Specific Language Impairment (SLI): Strengths and Difficulties in Social, Emotional and Behavioral Functioning. Research in Developmental Disabilities, 34, 4161-4169. https://doi.org/10.1016/j.ridd.2013.08.043

[34] Hvolby, A. (2015) Associations of Sleep Disturbance with ADHD: Implications for Treatment. Attention Deficit and Hyperactivity Disorders, 7, 1-18.

https://doi.org/10.1007/s12402-014-0151-0

[35] Constantin, E., Low, N.C.P., Dugas, E., Karp, I. and O’Loughlin, J. (2015) Association between Childhood Sleep-Disordered Breathing and Disruptive Behavior Disorders in Childhood and Adolescence. Behavioral Sleep Medicine, 13, 442-454. https://doi.org/10.1080/15402002.2014.940106

[36] Wajszilber, D., Santiseban, J.A. and Gruber, R. (2018) Sleep Disorders in Patients with ADHD: Impact and Management Challenges. Nature and Science of Sleep, 10, 453-480. https://doi.org/10.2147/NSS.S163074

[37] Oppositional Defiant Disorder. https://www.aacap.org/AACAP/Families_and_Youth/Facts_for_Families/FFF-Guid e/Children-With-Oppositional-Defiant-Disorder-072.aspx

[38] López-Villalobos, J.A., Andrés-De Llano, J.M., Rodríguez-Molinero, L., Garrido-Redondo, M., Sacristán-Martín, A.M., Martínez-Rivera, M.T., Alberola-López, S. and Sánchez-Azón, M.I. (2014) Prevalence of Oppositional Defiant Disorder in Spain. Revista de Psiquiatría y Salud Mental (English Edition), 7, 80-87. https://doi.org/10.1016/j.rpsmen.2014.02.006

[39] Antisocial Personality Disorder. https://www.health.harvard.edu/a_to_z/antisocial-personality-disorder-a-to-z

[40] Weiner, L., Perroud, N. and Weibel, S. (2019) Attention Deficit Hyperactivity Disorder and Borderline Personality Disorder in Adults: A Review of Their Links and Risks. Neuropsychiatric Disease and Treatment, 15, 3115-3129. https://doi.org/10.2147/NDT.S192871

[41] Quinn, P.O. (2005) Treating Adolescent Girls and Women with ADHD: Gender-Specific Issues. Journal of Clinical Psychology, 61, 579-587.

https://doi.org/10.1002/jclp.20121

[42] DSM-5. https://www.psychiatry.org/psychiatrists/practice/dsm

[43] Santa Rita, T.H., Barra, R.B., Peixoto, G.P., Mesquita, P.G. and Barra, G.B. (2017) Association between Suspected Zika Virus Disease during Pregnancy and Giving Birth to a Newborn with Congenital Microcephaly: A Matched Case-Control Study. BMC Research Notes, 10, 457. https://doi.org/10.1186/s13104-017-2796-1

[44] Culpepper, L. (2006) Primary Care Treatment of Attention-Deficit/Hyperactivity Disorder. Journal of Clinical Psychiatry, 67, 51-58.

[45] D'Agati, E., Curatolo, P. and Mazzone, L. (2019) Comorbidity between ADHD and Anxiety Disorders across the Lifespan. International Journal of Psychiatry in Clinical Practice, 23, 238-244. https://doi.org/10.1080/13651501.2019.1628277

[46] Nadeau, K., Littman, E. and Quinn, P. (2015) Understanding Girls with ADHD: 
How They Feel and Why They Do What They Do. 2nd Edition, Advantage Books.

[47] What Is Intellectual Disability?

https://www.psychiatry.org/patients-families/intellectual-disability/what-is-intellect ual-disability

[48] Ahuja, A., Martin, J., Langley, K. and Thapar, A. (2013) Intellectual Disability in Children with Attention Deficit Hyperactivity Disorder. The Journal of Pediatrics, 163, 890-895.e1. https://doi.org/10.1016/j.jpeds.2013.02.043

[49] van Emmerik-van Oortmerssen, K., van de Glind, G., van den Brink, W., Smit, F., Crunelle, C.L., Swets, M. and Schoevers, R.A. (2012) Prevalence of Attention-Deficit Hyperactivity Disorder in Substance Use Disorder Patients: A Meta-Analysis and Meta-Regression Analysis. Drug and Alcohol Dependence, 122, 11-19.

https://doi.org/10.1016/j.drugalcdep.2011.12.007

[50] Zulauf, C.A., Sprich, S.E., Safren, S.A. and Wilens, T.E. (2014) The Complicated Relationship between Attention Deficit/Hyperactivity Disorder and Substance Use Disorders. Current Psychiatry Reports, 16, 436.

https://doi.org/10.1007/s11920-013-0436-6

[51] Skirrow, C., Hosang, G.M., Farmer, A.E. and Asherson, P. (2012) An Update on the Debated Association between ADHD and Bipolar Disorder across the Lifespan. Journal of Affective Disorders, 141, 143-159. https://doi.org/10.1016/j.jad.2012.04.003

[52] ADHD Institute (2020) Neurocognitive Markers of Late-Onset ADHD in Children and Adolescents.

[53] Meinzer, M.C., LeMoine, K.A., Howard, A.L., Stehli, A., Arnold, L.E., Hechtman, L., Hinshaw, S.P., Molina, B.S.G., Murray, D.W., Sibley, M.H., Swanson, J.M., Tamm, L. and Chronis-Tuscano, A. (2020) Childhood ADHD and Involvement in Early Pregnancy: Mechanisms of Risk. Journal of Attention Disorders, 24, 1955-1965. https://doi.org/10.1177/1087054717730610

[54] Mood Disorders \& ADHD. https://www.healthychildren.org/English/health-issues/conditions/adhd/Pages/Moo d-Disorders-ADHD.aspx

[55] Swain, J.E. and Leckman, J.F. (2005) Tourette Syndrome and Tic Disorders. Psychiatry (Edgmont), 2, 26-36.

[56] Hartley, S.L. and Sikora, D.M. (2009) Which DSM-IV-TR Criteria Best Differentiate High-Functioning Autism Spectrum Disorder from ADHD and Anxiety Disorders in Older Children? Autism: The International Journal of Research and Practice, 13, 485-509. https://doi.org/10.1177/1362361309335717

[57] Nijmeijer, J.S., Minderaa, R.B., Buitelaar, J.K., Mulligan, A., Hartman, C.A. and Hoekstra, P.J. (2008) Attention-Deficit/Hyperactivity Disorder and Social Dysfunctioning. Clinical Psychology Review, 28, 692-708. https://doi.org/10.1016/j.cpr.2007.10.003

[58] Williams, D.L. and Minshew, N.J. (2007) Understanding Autism and Related Disorders: What Has Imaging Taught us? Neuroimaging Clinics of North America, 17, 495-509. https://doi.org/10.1016/j.nic.2007.07.007 